\title{
Erratum to: Characterising and comparing drug-dispensing practices at animal health outlets in the Rift Valley, Kenya: an exploratory analysis (part II)
}

\author{
L. E. Higham ${ }^{1,2} \cdot$ W. Ongeri ${ }^{3} \cdot$ K. Asena $^{3}$ - M. V. Thrusfield ${ }^{4}$
}

Published online: 13 October 2016

(C) Springer Science+Business Media Dordrecht 2016

Erratum to: Trop Anim Health Prod

DOI: 10.1007/s11250-016-1137-z. Epub 2016

June 22

The authors regret that Figure 6 of the original article was published online with an error. The confidence intervals in the published version exceed 1.00. The authors would like to point out that this error does not affect the interpretation of results in the article.

The corrected figure is presented below.

Also, the originally published article has been corrected.

The online version of the original article can be found at http://dx.doi. org/10.1007/s11250-016-1137-z.

L. E. Higham

laura.higham@faifarms.com

FAI Farms Ltd, The Field Station, Wytham, Oxford OX2 8QJ, UK

2 Division of Infection and PathwayMedicine, Deanery of Biomedical Sciences, College of Medicine and Veterinary Medicine,

Chancellor's Building, 49 Little France Crescent, Edinburgh EH16 4SB, UK

3 Sidai Africa Ltd., Nairobi, Kenya

4 Veterinary Clinical Sciences, Royal (Dick) School of Veterinary Studies, University of Edinburgh, Easter Bush EH25 9RG, UK 
Knowledge, attitudes and practices in dispensing veterinary drugs of staff at drug outlets with and without technically trained personnel in the workforce, in the Rift Valley, Kenya

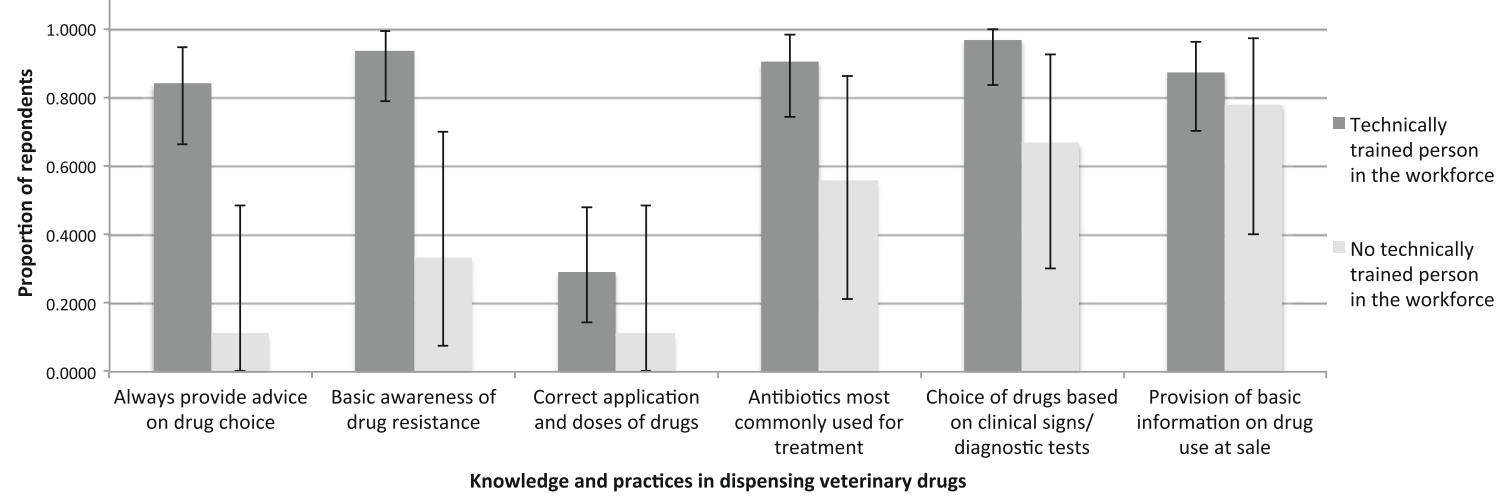

Fig. 6 Proportions with $95 \%$ confidence intervals of respondents from animal health outlets with and without technically trained personnel in the workforce, with knowledge, attitudes and practices consistent with responsible veterinary drug use in the Rift Valley, Kenya 